\title{
Application of passengers' thermoregulation integral model used in the evaluation of thermal comfort in vehicles compartment equipped with internal curtains
}

\author{
Eusébio Conceição ${ }^{1 *}$, João Gomes ${ }^{2}$, M. Manuela Lúcio $^{1}$, M. Inês Conceição ${ }^{3}$, André Ramos ${ }^{1}$, and Hazim Awbi ${ }^{4}$ \\ ${ }^{1}$ FCT - Universidade do Algarve, Campus de Gambelas, 8005-139 Faro, Portugal \\ ${ }^{2}$ CINTAL, Campus de Gambelas, 8005-139 Faro, Portugal \\ ${ }^{3}$ Instituto Superior Técnico, Av. Rovisco Pais, 1049-001 Lisboa, Portugal \\ ${ }^{4}$ School of Built Environment, University of Reading, Reading, RG6 6AW, United Kingdom
}

\begin{abstract}
This work evaluates the passengers thermal comfort level inside a vehicles compartment. The numerical study, made in winter conditions, consider a bus indoor environment equipped with internal curtains, internal seats, lateral panels, ceiling, floor and occupied by 52 passengers. The numerical model considers the passengers and vehicle grid generation, passengers body and clothing thermal response and passengers thermal comfort level. The grid generation is used to evaluate the view factors and Mean Radiant Temperature that the passengers are subjected. In this calculus the passengers and the vehicles surfaces shading devices are considered. The thermal response numerical models consider the energy and mass balance integral equations. The thermal comfort evaluation considers the heat produced inside the body and the heat exchange between the body and the environment. The human body numerical model considers also the thermoregulatory system to control the temperature. The numerical model is used to evaluate the thermal comfort level that seated passengers are subjected in a bus equipped with asymmetrical warm curtains. Three Cases studies were developed: the first one considers the temperature curtains equal to the indoor bus surfaces, while the other two consider higher temperatures values. All Cases are thermally comfortable according to the standards.
\end{abstract}

\section{Introduction}

The people spend part of the time inside vehicles, as bus, trains, and others vehicles. This kind of vehicles can provide acceptable thermal conditions, using Heating, Ventilating and Air-Conditioning system. This system can promote similar thermal comfort conditions to the occupants, however external environmental conditions, as the solar radiation, can provide asymmetrical conditions to the occupants. In general, internal curtains are used to reduce this uncomfortable conditions. The curtains subjected to solar radiation reduce the inlet solar radiation and can be used as radiative surfaces that, in winter conditions, can improve the thermal comfort conditions that the occupants are subjected.

To evaluate the thermal discomfort and thermal comfort levels, different models were developing [1]. These models, inclusively, are published in international standards [2,3]. The local thermal discomfort, as asymmetrical thermal conditions, can promote uncomfortable thermal conditions, as Draught Risks and others. The works of Conceição et al. [4] and Conceição [5] analyzed in detail these uncomfortable problems using experimental and numerical methodologies. The thermal comfort level, developed by Fanger [6], and showed in the standards [2,3], is evaluated using Predicted Mean Vote (PMV) index and Predicted
Percentage of Dissatisfied (PPD) index. Applications using the thermal comfort level, adaptive thermal comfort levels and empirical models can be analysed in, the works of Conceição et al. [7,8]

The software applied in this work simulates the Vehicle Thermal Response and the Human Thermal Response numerical models, that includes the human thermoregulatory system. The first one evaluates the vehicle design, using Computer Aid Design, and calculates the distribution of temperature and solar radiation inside vehicle spaces, in particular, the passenger compartment. In the vehicle thermal behavior numerical models, have been given special attention to the passenger compartment (main and interior bodies and windows) and thermal phenomena (radiation, convection, human generation, glass radiative properties, air renovation and others).

Some works related with the Vehicle Thermal Response and the evaluation of thermal comfort were developed in the last years. Some examples about the thermal comfort evaluation can be analyzed in Walgama et al. [9] and Rugh et al. [10], while the numerical simulation of bus and passengers can be seen in Riachi [11] and Mezrhab and Bouzidi [12].

Vehicle Thermal Response numerical model is based on the Building Thermal Response. The Building Thermal Response, developed in the last years,

* Corresponding author: econcei@ualg.pt 
considers energy and mass balance integral equations. Some applications can be seen in Conceição et al. [13], for an internal energy analysis, in Conceição and Lúcio [14], for an application of shading devices, in Conceição and Lúcio [15], for a passive analysis, in Conceição and Lúcio [16], for both passive and active analysis, and for a set of validations in Conceição and Lúcio [17].

The Human Thermal Response numerical model is used to evaluate the passengers thermal comfort level. This numerical model, based on a human multi-node comfort model, considers energy and mass balance integral equations and the Thermoregulatory system based in the work of Stolwijk and Hardy [18]. More details can be seen in studies of Conceição et al. [19, 20].

The radiative heat exchanges numerical model between the vehicle and the passengers, based on Mean Radiant Temperature method, is developed and applied in the works of Conceição et al. [6,21]. The numerical model that simulates the vehicles thermal behavior calculates not only the solar radiation incident in the internal and external surfaces, but also the radiative heat exchange between internal, in each space, and external surfaces, between vehicle and surrounding bodies. In the radiative calculus are considered, in the internal and external calculus, the shading effect. The radiative heat exchange applications can be seen in Conceição and Lúcio [15].

The present work is a continuation of the works developed in Conceição et al. [22,23]. Others studies with the same topic can be analysed in Shek and Chan [24] and Velt and Daanen [25].

In the present numerical study is analysed, in detail, the thermal comfort of the passengers seated inside a bus, on both sides with windows, without and with internal curtains on the left window subjected to solar radiation. The view factors and the radiative heat exchanges by radiation between the different human body sections and the surroundings surfaces, namely, the seats, lateral panels, ceiling, floor, curtains, and others, are considered.

\section{Occupant mathematical model}

The numerical model, that simulates the Human Thermal Response, that works in transient conditions, is based on energy and mass balance integral equations. The equations are based on conduction, convection and radiation phenomena and are solved by the RungeKutta-Felberg method with error control.

The human body geometry is generated using the empirical equations and the equation system is generated in accordance with the inputs, namely, in accordance with the number of elements and layers considered in the human body and in the clothing level defined in the numerical simulation.

All coefficients used in these equations are evaluated by sub-models that calculate the view factors, radiative heat exchanges, clothing level, human thermophysiology and heat and mass transfer coefficients by convection using empirical expressions.

The occupants are divided in 25 cylindrical or spherical elements and each element is sub-divided in
12 cylindrical or spherical layers and could be still protected of the external environment through several layers of clothing.

\section{Vehicle mathematical model}

The numerical model that simulates the Vehicle Thermal Behaviour and work in transient conditions is based on energy and mass balance integral equations. The equations are based on conduction, convection and radiation phenomena and are solved by the RungeKutta-Felberg method with error control.

The equations are developed through the Computer Aided Design techniques. This methodology, that considers a vehicle with complex topology, can be used to simulate more realistic vehicles designs.

All coefficients used in these equations are evaluated by sub-models that calculate the glass radiative properties, occupation cycle, ventilation strategy and heat and mass transfer coefficients by convection using empirical expressions.

The Vehicle Thermal Behavior considers the convective (natural, forced and mixed), conductive (in the main bodies divided in several layers), radiative (shortwave and long wave radiation outside and inside the vehicle) and mass transfer (inside the compartments) phenomena.

The vehicle, in general, is divided into several compartments (passengers, luggage and motor), main bodies (panels, doors, ceiling and floor), interior bodies (benches and motors) and glasses (windows).

\section{Heat exchanges by radiation}

The heat exchange by radiation numerical model, that uses the view factors calculated between the human body and the vehicles surrounding surfaces, is based on the Mean Radiant Temperature method.

In the methodology used in view factors determination, each vehicle surface is sub-divided into several small areas and each human body element, with inclinations and dimensions equal to the respective body, are divided into infinitesimal areas. It is considered the shading effect caused by the surrounding surfaces, namely the vehicle surfaces and the occupant's bodies.

The human body considers:

- Heat exchanges between the human body sections and the surrounding surfaces (main and interiors bodies and glass);

- Heat exchanges between the human bodies sections of each passenger and between the human bodies sections of different passengers.

- The vehicle body considers:

- Heat exchanges between the vehicle surfaces (main and interiors bodies and glass) itself;

- Heat exchanges between the vehicle surfaces (main and interiors bodies and glass) and the passengers; 
- Heat exchanges between the vehicle surfaces (main and interiors bodies and glass) and the external surfaces (floor, environment, and fire front).

The Mean Radiant Temperature method, with correction, calculates, step by step, the Mean Radiant Temperature, using the human body and vehicles bodies, calculated in each iteration, and the precalculated view factors.

\section{Simplified bus model}

In the passenger compartment of the bus studied is considered two ventilation ducts over the seats, 99 main bodies, 18 glazed window, 9 curtains and 105 interior bodies (as can be seen in Fig. 1 and Fig. 2). The bus is occupied by 52 passengers. Each passenger has $1.7 \mathrm{~m}$ of height, $70 \mathrm{~kg}$ of weight, 1 met of activity level and $1 \mathrm{clo}$ of clothing level.

Each of these surfaces, vehicle and passengers, in order to evaluate the view factors, is divided into several infinitesimal areas. In general, all vehicle surfaces are subdivided in a minimum of 100 elementary areas. Regarding the passengers:

- The spherical head is divided in 64 elementary areas (a grid in the azimuthal angle direction of 8 divisions and a grid in the polar angle direction of 8 divisions);

- The cylindrical elements are also divided in 64 elements (a grid in the longitudinal direction of 8 divisions and a grid in the radial direction of 8 divisions).

In the geometry definition, all vehicles surfaces (main bodies and transparent bodies) are in contact. However, in the interior bodies only the seats, defined by a vertical and an inclined surface, are defined.

All elements of the passengers are arranged in similar way to the seat human body posture. The neck, the arms and the legs, both divided in four sections, are connected to the trunk with dimensions and angles similar to the human body sections. The head is connected to the neck, the hands are connected to the arms and the feet are connected to the legs. In the neck, shoulders, elbows, hips, knees and ankles, they are placed rotation elements. The dimensions and inclination of each element are obtained using a numerical model based on the human body weight and height. All passengers are not in contact between them and all passengers are not in contact with the seat and with all vehicle surfaces.

In these calculations, the air temperature and relative humidity are, respectively, $20^{\circ} \mathrm{C}$ and $50 \%$, while the internal vehicle surfaces temperatures are $20^{\circ} \mathrm{C}$.

This work is divided in three parts:

- The temperature of the internal left curtains is $20^{\circ} \mathrm{C}$ (Case A);

- The temperature of the internal left curtains is $40^{\circ} \mathrm{C}$ (Case B);

- The temperature of the internal left curtains is $60^{\circ} \mathrm{C}$ (Case C).

The scheme of a bus and the 52 occupants is presented in Fig. 1 and Fig. 2. Fig. 1 shows the details of the visualization of the external vehicle surfaces, while Fig. 2 shows the details of the visualization of the external passenger surfaces.

In Fig. 3, the location of the occupants in the bus and the identification of symbols in Fig. 4 to Fig. 7 are presented.

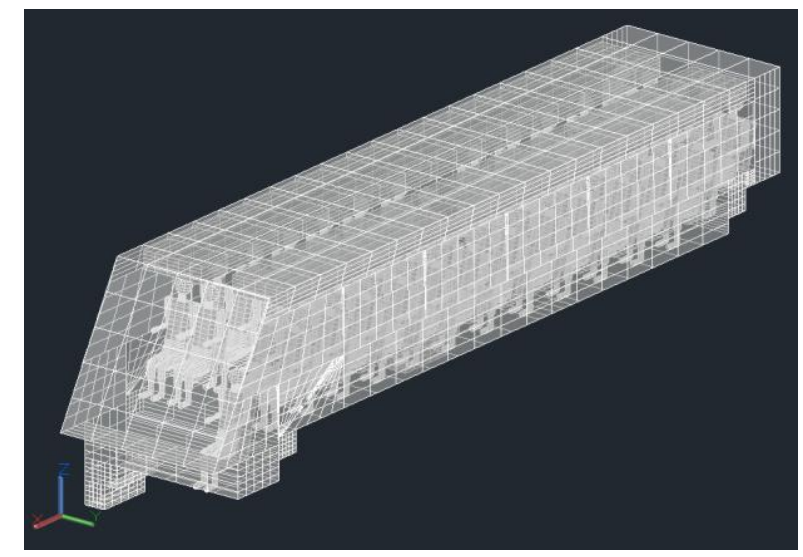

Fig. 1. Scheme of a bus and the 52 occupants: detailed visualization of the external vehicle surfaces.

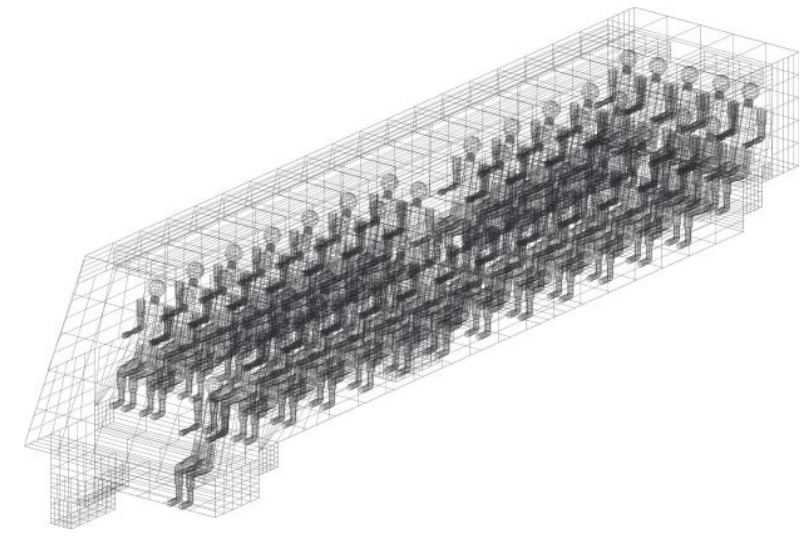

Fig. 2. Scheme of a bus and the 52 occupants: detailed visualization of the occupants.

\begin{tabular}{|c|c|c|c|}
\hline \multicolumn{4}{|l|}{$* 1$} \\
\hline$\cdot 5$ & $\cdot 4$ & $\cdot 3$ & $\cdot 2$ \\
\hline$\cdot 9$ & $\circ 8$ & .7 & $\Delta 6$ \\
\hline - 13 & ○ 12 & - 11 & $\triangle 10$ \\
\hline$\diamond 17$ & $\circ 16$ & ㅁ 15 & $\Delta 14$ \\
\hline$\diamond 21$ & $\circ 20$ & $\square 19$ & $\triangle 18$ \\
\hline$\diamond 25$ & ○ 24 & $\square 23$ & $\triangle 22$ \\
\hline$\diamond 29$ & ○ 28 & $\square 27$ & $\triangle 26$ \\
\hline$\diamond 31$ & $\circ 30$ & & \\
\hline$\diamond 35$ & ○ 34 & $\square 33$ & $\triangle 32$ \\
\hline$\diamond 39$ & $\bigcirc 38$ & $\square 37$ & $\triangle 36$ \\
\hline$\diamond 43$ & $\bigcirc 42$ & $\square 41$ & $\triangle 40$ \\
\hline$\diamond 47$ & $\bigcirc 46$ & $\square 45$ & $\triangle 44$ \\
\hline$\diamond 52$ & $\bigcirc 51+50$ & $\square 49$ & $\triangle 48$ \\
\hline
\end{tabular}

Fig. 3. Location of the occupants in the bus and identification of symbols in the Fig. 4 to Fig. 7. 


\section{Results and discussion}

In Fig. 4, it is presented the Mean Radiant Temperature (MRT) that each occupant is subjected for Case A (point a), Case B (point b), and Case C (point c).

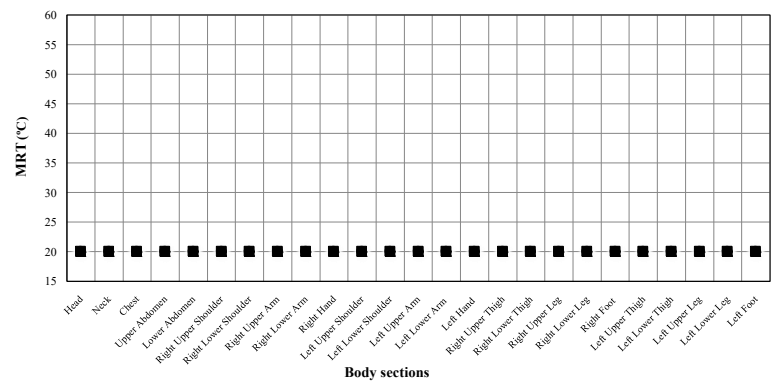

a)

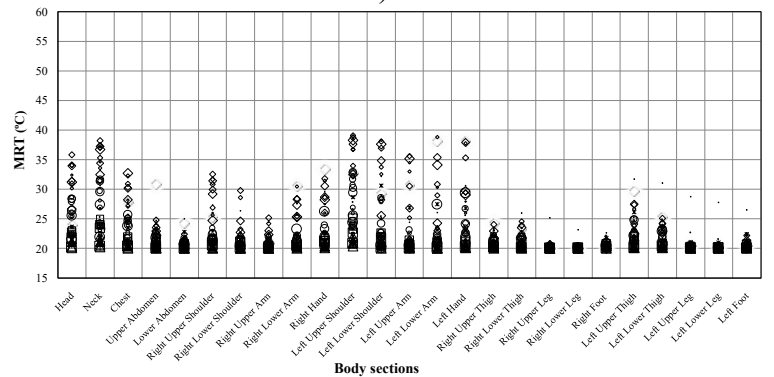

b)

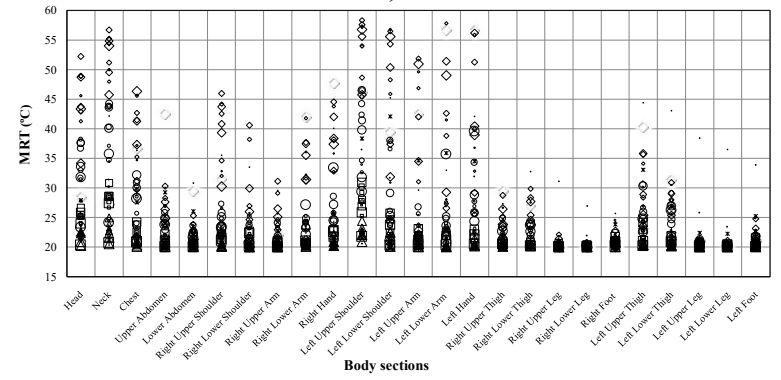

c)

Fig. 4. Mean Radiant Temperature (MRT) that each occupant is subjected for: a) Case A; b) Case B; c) Case C.

Regarding to the results obtained is possible to verify that:

- When the curtain surface temperature increases the Mean Radiant Temperature increases;

- The Mean Radiant Temperature is highest for the passenger located near the left side of the vehicle;

- The Mean Radiant Temperature is higher for the left side passenger sections than for the right side passenger sections;

- The Mean Radiant Temperature is higher in upper passenger sections than in lower passenger sections. In Fig. 5, it is presented the skin temperature (Tskin) that each occupant is subjected for Case A (point a), Case B (point b), and Case C (point c). The PMV and the PPV values that each occupant is subjected are presented, respectively, in Fig. 6 and Fig. 7.

The skin temperature, that each occupant section is subjected, increases when the Mean Radiant Temperature increases. The highest values are verified in sections not protected by the clothing as the head, neck and hands.

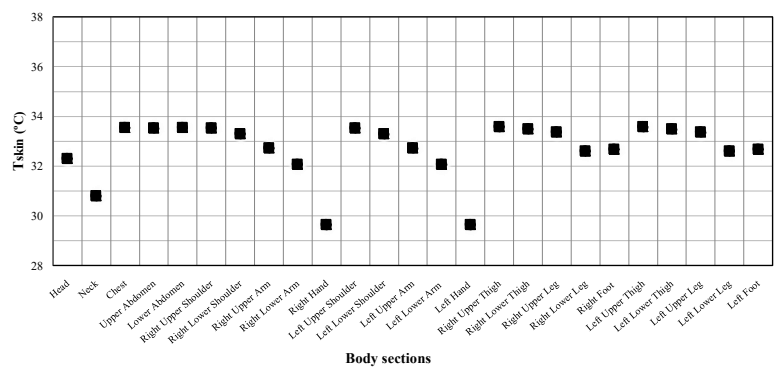

a)

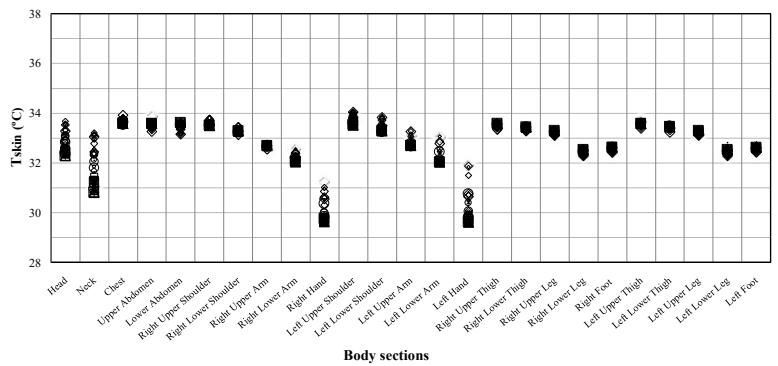

b)

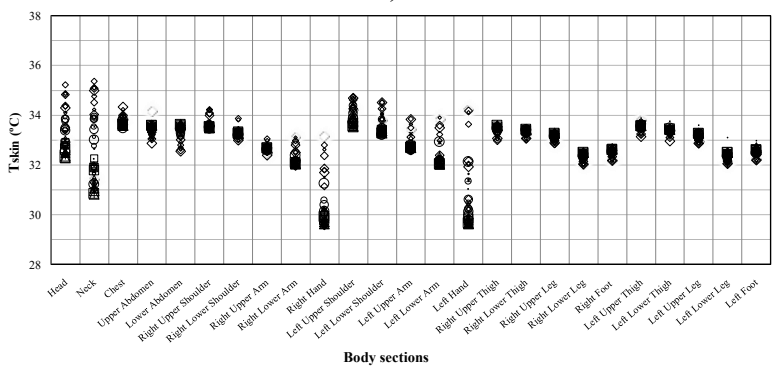

c)

Fig. 5. Skin temperature (Tskin) that each occupant is subjected for: a) Case A; b) Case B; c) Case C.

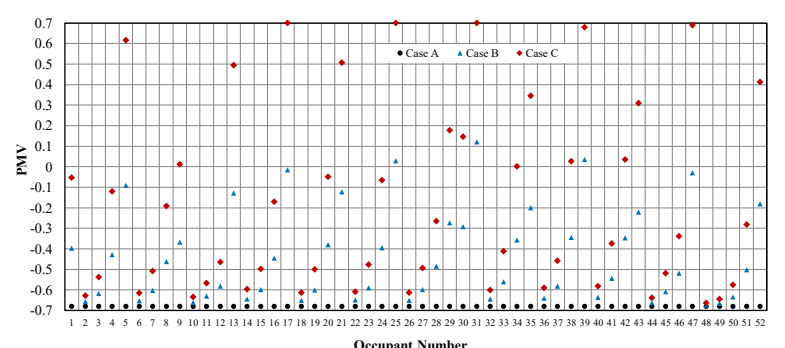

Fig. 6. PMV values that the occupants are subjected.

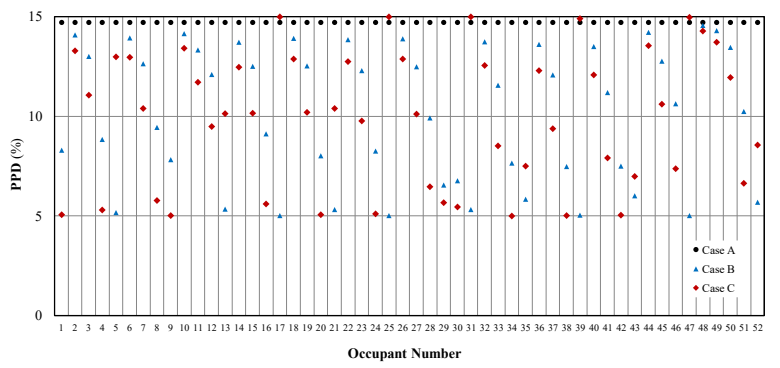

Fig. 7. PPD values that the occupants are subjected.

The thermal comfort level for the Case $\mathrm{A}$ is acceptable, regarding to the category $\mathrm{C}$ [3], for all occupants, by negative PMV values.

When the curtain surface temperature increases, Case B, the thermal comfort level of the occupants improves and the occupant seated near the warm curtain surface is comfortable according to the Categories A and 
B [3], by negative PMV values. However, the other occupants are comfortable according to the Category $\mathrm{C}$ [3], also by negative PMV values.

When the curtains surface temperature increases to $60^{\circ} \mathrm{C}$, Case $\mathrm{C}$, the thermal comfort of the occupant seated near the warm curtain is in accordance with the Category C [3], but by positive PMV values. However, the occupant seated near the right window is comfortable in accordance with the Category C [3], by negative PMV values, and the other occupants are comfortable according to the Categories A and B [3], by negative or positive PMV values.

Thus, regarding to results obtained, the warm curtains, subjected to solar radiation, can be used to improve the thermal comfort conditions of the occupants in winter conditions.

In future works, the influence of solar radiation that each passenger is subjected, also in winter conditions, will be analyzed.

\section{Conclusions}

In this study the application of passengers' thermoregulation integral model used in the evaluation of thermal comfort in vehicles compartment equipped with internal curtains was made. The study was made for winter conditions and considering three Cases study.

The numerical model was used to evaluate the thermal comfort level that seated passengers are subjected in a bus equipped with asymmetrical warm curtains.

The warm curtains, subjected to solar radiation, can be used to improve the thermal comfort conditions of the occupants in winter conditions. However, if the increase in the curtains temperature is high, then the thermal comfort conditions can be thermal uncomfortable for the occupants.

The authors would like to acknowledge to the project (SAICTALG/39586/2018) from Algarve Regional Operational Program (CRESC Algarve 2020), under the PORTUGAL 2020 Partnership Agreement, through the European Regional Development Fund (ERDF) and the National Science and Technology Foundation (FCT).

\section{References}

1. Awbi, Ventilation of Buildings (Routledge, 2004)

2. ANSI/ASHRAE-55 Standard, Thermal environmental conditions for human occupancy (ASHRAE, Atlanta, 2017)

3. ISO 7730, Ergonomics of the thermal environment Analytical determination and interpretation of thermal comfort using calculation of the PMV and PPD indices and local thermal comfort criteria (International Organisation for Standardisation, Geneva, 2005)

4. E. Conceição, M. Lúcio, V. Vicente, V. Rosão. Int. J. Vent. 7, 267-277 (2008)

5. E. Conceição, Evaluation of thermal comfort and local discomfort conditions using the numerical modelling of the human and clothing thermal system, in Proceedings of $7^{\text {th }}$ International Conference on Air Distribution in Room, ROOMVENT 2000, 9-12 July 2000, Reading, UK (2000)

6. P. Fanger, Thermal comfort (Danish Technical Press, Copenhagen, 1970)

7. E. Conceição, J. Gomes, A. Ruano. IFAC PapersOnLine 51, 20-25 (2018)

8. E. Conceição, M. Lúcio, A. Ruano, E. Crispim. Build. Environ. 44, 871-877 (2009)

9. C. Walgama, S. Fackrell, M. Karimi, A. Fartaj, G. Rankin. P. I. Mech. Eng. D-J. Aut. 5, 543-562 (2006)

10. J. Raugh. R. Farrington, D. Bharathan, A. Vlahinos, R. Burke, C. Huinzenga, H. Zhang. Eur. J. Appl. Physiol. 92, 721-727 (2004)

11. Y. Riachi. Int. J. Environ. Prot. Policy 2, 1-8 (2014)

12. A. Mezrhab, M. Bouzidi. Appl. Therm. Eng. 26, 1697-1704 (2006)

13. E. Conceição, M. Lúcio, M. Lopes. WSEAS Trans. Environ. Dev. 4, 644-654 (2008)

14. E. Conceição, M. Lúcio. Indoor Built Environ. 19, 657-667 (2010)

15. E. Conceição, M. Lúcio. Indoor Built Environ. 18, 41-51 (2009)

16. E. Conceição, M. Lúcio. Build. Simul. 3, 245-261 (2010)

17. E. Conceição, M. Lúcio, Numerical study of thermal response of school buildings in summer conditions, in Proceedings of the $8^{\text {th }}$ International Conference and Exhibition on Healthy Buildings (HB 2006), 4-8 June 2006, Lisbon, Portugal (2006)

18. J. Stolwijk, J. Hardy. Pflugers Arch. Gesamte Physiol. Menschen Tiere 291, 129-162 (1966)

19. E. Conceição, M. Lúcio, H. Awbi. Build. Simul. 6, 51-67 (2013)

20. E. Conceição, S. Rosa, A. Custódio, R. Andrade, M. Meira, M. Lúcio. HVACR Res. 16, 401-412 (2010)

21. F. Incropera, D. De Witt, T. Bergman, A. Lavine. Principles of heat and mass transfer (Wiley, 2013)

22. E. Conceição, M. Silva, J. André, D. Viegas. Int. J. Veh. Des. 24, 372-387 (2000)

23. E. Conceição, M. Silva, D. Viegas. HVACR Res. 3, 311-323 (1997)

24. K. Shek, W. Chan. Sci. Total Environ. 389, 277-82 (2008)

25. K. Velt, H. Daanen. Appl. Ergon. 62, 72-76 (2017) 